\title{
COMPARING EFFICACY OF TWO TECHNIQUES IN PSANB- POSTERIOR SUPERIOR ALVEOLAR NERVE BLOCK
}

\author{
Muniappan Harihara Sabari1, Gopalakrishnan Suresh Kumar², Amalorpavanathan Andrew ${ }^{3}$ \\ ${ }^{1}$ Assistant Professor, Department of Dental Surgery, Tirunelveli Medical College Hospital, Tirunelveli, Tamilnadu. \\ ${ }^{2}$ Associate Professor, Department of Dental Surgery, Tirunelveli Medical College Hospital, Tirunelveli, Tamilnadu. \\ 3 Professor and HOD, Department of Dental Surgery, Tirunelveli Medical College Hospital, Tirunelveli, Tamilnadu.
}

\section{ABSTRACT}

\section{BACKGROUND}

Local anaesthesia is the back bone of dentistry, as it allays the most common fear of pain among the dental patients. Many techniques were available to achieve anaesthesia for posterior maxilla. We compared two techniques of posterior superior alveolar nerve block (PSANB), its efficacy in achieving anaesthesia in posterior maxilla.

Aim- The aim of the study was to compare the efficacy of "the straight needle technique" with that of the "bent needle technique" for PSANB.

\section{MATERIALS AND METHODS}

This is a randomised double-blinded trial. A group of 100 patients were randomised and divided into two categories, each consisting of 50 patients. Group A patients received PSANB via straight needle technique, while Group B patients received PSANB via bent needle technique. A 26-gauge long needle $(38 \mathrm{~mm}$ ) was used for the study. $2 \mathrm{~mL}$ of $2 \%$ lignocaine hydrochloride with $1: 200,000$ adrenaline was used to give the block in both the groups. Objective symptoms were evaluated by a single investigator. Cold test using ice was used to evaluate pulpal status of the patients. Data obtained was subjected to statistical analysis. Sample size was considered conveniently.

\section{RESULTS}

Out of the 100 nerve blocks, 14 failed (Group A: 3 and B: 11), suggesting technique A (Straight Needle Technique) was more successful than B (bent needle) in this study and this was statistically significant $(p=0.021)$. No statistical difference was noted between the two groups in obtaining gingival anaesthesia in the first molar region, also in second and third molar regions. We did not encounter any complications in our study.

\section{CONCLUSION}

The study concludes that the PSANB using the straight needle technique can be safely and routinely used to achieve profound anaesthesia in the maxillary molar regions.

\section{KEYWORDS}

Posterior Superior Alveolar Nerve Block; Straight Needle Technique; Bent Needle Technique; Maxillary Molars.

HOW TO CITE THIS ARTICLE: Sabari MH, Kumar GS, Andrew A. Comparing efficacy of two techniques in PSANB- posterior superior alveolar nerve block. J. Evolution Med. Dent. Sci. 2018;7(13):1596-1598, DOI: 10.14260/jemds/2018/361

\section{BACKGROUND}

Extraction of teeth is the most common surgical procedure done by all general dentists and even oral surgeons. Usually, extraction of teeth is carried out under local anaesthesia. Infiltration procedure is the most common technique of anaesthesia for administration of local anaesthesia solution in maxilla. Nerve block techniques are available for maxilla, but we are reluctant to administer the same routinely because of fear of complications, minimal training attained and uncertainty about its efficacy. PSANB- posterior superior alveolar nerve block is such a kind of nerve block in maxilla. The aim of the study was to compare the efficacy of "the straight needle technique" with that of the "bent needle technique" for PSANB.

'Financial or Other Competing Interest': None.

Submission 28-12-2017, Peer Review 09-03-2018,

Acceptance 16-03-2018, Published 26-03-2018.

Corresponding Author:

Dr. Gopalakrishnan Suresh Kumar,

\#48/136, Kovil Street, Kurinji Nagar,

Reserve Line Post, Mudurai-625014, Tamilnadu.

E-mail:omfs007@yahoo.in

DOI: $10.14260 /$ jemds $/ 2018 / 361$

\section{(c) (i) $(3)$}

\section{MATERIALS AND METHODS}

The clinical study approved by the Institutional Ethical and Research Committee was conducted among the patients who reported for extraction of maxillary molars to the Department of Dental Surgery. A group of 100 patients were randomised and divided into two categories, each consisting of 50 patients in the ratio of 1 : 1 . Simple randomisation was done using computer generated random table. Group A patients received PSANB via straight needle technique, while Group B patients received PSANB via bent needle technique.

Sample size is considered conveniently. Patients of both genders above the age of 18 years were included in the study. Patients having inflammation, infection at the site of injection, pregnant women and patients who were medically compromised were excluded from the study. In case if the second molar is missing, those patients were excluded from the study. A 26-gauge long needle (38 $\mathrm{mm})$ is used for the study. A $2 \mathrm{~mL}$ of $2 \%$ lignocaine hydrochloride with $1: 200,000$ adrenaline was used to give the block in both the groups.

All patients were unaware of the type of injection. All the blocks were administrated by an unmasked dental surgeon. A single masked dental surgeon who was blinded to the group evaluated the objective symptoms. The study is a randomised double-blind one. Sample size is convenient. The following symptoms were evaluated: periosteal elevator was used to 
assess pain on the buccal aspect of the maxillary molars, cold test for pulpal anaesthesia and pain during extractions. In case of failure of the block, the same technique was repeated to achieve anaesthesia. If the anaesthesia was not achieved following a single repeat injection, the block was considered to be a failure.

Statistical analysis was done using SPSS. Fisher's exact test was used to compare the characteristics of the two groups. $\mathrm{P}<0.05$ was considered to be statistically significant.
Out of the 100 nerve blocks, 14 failed (Group A: 3 and B: 11), suggesting technique A (Straight Needle Technique) was more successful than B (Bent Needle) in this study and this was statistically significant $(\mathrm{p}=0.021)$, Table 3 .

No statistical difference between the two groups in obtaining gingival anaesthesia in the first molar region, Table 1.

No statistical difference between the two groups in obtaining gingival anaesthesia in the second and third molar regions, Table 2.

\section{RESULTS}

\begin{tabular}{|c|c|c|c|c|c|}
\hline & & Gingival Symptoms in 1st Molar Region & & Total & P value \\
\hline & & Present & Absent & Iotal & P value \\
\hline \multirow{2}{*}{ Group } & Straight Needle & 46 & 1 & 47 & \multirow{2}{*}{0.325} \\
\hline & Bent Needle & 36 & 3 & 39 & \\
\hline \multicolumn{6}{|c|}{ Table 1} \\
\hline
\end{tabular}

Fisher's exact test.

Cross tabulation between groups for gingival symptoms in first molar region. $\mathrm{P}$ value not significant. There is no statistical difference between the groups.

\begin{tabular}{|c|c|c|c|c|c|}
\hline & & Gingival Symptoms in 2nd and 3rd Molars & & \multirow{2}{*}{ Total } & \multirow{2}{*}{$P$ value } \\
\hline & & Present & Absent & & \\
\hline \multirow[t]{2}{*}{ Group } & Straight needle & 46 & 1 & 47 & \multirow[b]{2}{*}{1.000} \\
\hline & Bent needle & 38 & 1 & 39 & \\
\hline \multicolumn{6}{|c|}{ Table 2} \\
\hline
\end{tabular}

Fisher's exact test.

Cross tabulation between groups for gingival symptoms in Second and Third molar region. P value not significant. There is no statistical difference between the groups.

\begin{tabular}{|c|c|c|c|c|c|}
\hline & & Objective Dental Symptoms & \multirow{2}{*}{ Total } & \multirow{2}{*}{ P value } \\
\hline & & Success & Failure & 50 & \multirow{2}{*}{0.021} \\
\hline Group & Straight needle & 47 & 3 & 11 & 50 \\
\hline
\end{tabular}

Pearson chi-square test.

Cross tabulation between groups for presence of objective dental symptoms. P value 0.021 significant. There is statistical difference between the groups. Straight needle technique is better than the bent needle technique.

Table 4 and 5 shows no Demographic Differences between the Groups

\begin{tabular}{|c|c|c|c|c|}
\hline & & \multicolumn{2}{|c|}{ Gender } & \multirow{2}{*}{ Total } \\
\hline & & Male & Female & 50 \\
\hline Group & Straight needle & 28 & 22 & 50 \\
\hline & Bent needle & 23 & 27 & 50 \\
\hline
\end{tabular}

\begin{tabular}{|c|c|c|c|c|}
\hline \multicolumn{2}{|c|}{ Group Statistics } & & & Std. Deviation \\
\hline & Group & N & Mean & 13.61278 \\
\hline Age & Straight needle & 50 & 51.28 & 14.86242 \\
\hline & Bent needle & 50 & 48.92 & \\
\hline
\end{tabular}

\section{DISCUSSION}

Many techniques for PSANB have been proposed by several authors. The target for every author seems to attain close deposition of the solution to the main trunk of the nerve before it enters the bone or deeper tissues. The target area for deposition of local anaesthetic solution is the posterior surface of maxilla midway between alveolar border and the orbital surface of maxilla, where the posterior-superior alveolar nerve enters.

Malamed described the most common straight needle technique for PSANB.[1] According to Malamed, this straight needle technique is successful in more than $95 \%$ cases of 
upper molars. Jorgensen and Hayden described the bent needle technique for PSANB.[2] They both described that this bent needle technique is more efficient and produces a higher success rate than the straight needle technique.

Pfeil et al used this straight needle technique which achieved $97 \%$ success rate for second molars, whereas it was 77\% for first molars.[3] Himashi et al showed $86 \%$ success rate for second and third molars, while a very low rate for first molars $(9 \%)$ might be due to the presence of middle superior alveolar nerves. ${ }^{[4]}$

An adequate amount of anaesthesia should be injected for the nerve block to be effective. Pfeil[3] et al in their study proved that anaesthetic success for the $1.8 \mathrm{~mL}$ volume of $2 \%$ lidocaine with 1:100,000 epinephrine was $97 \%$ for the second molar and $77 \%$ for the first molar. Anaesthetic success for the $3.6 \mathrm{~mL}$ volume of $2 \%$ lidocaine with 1:100,000 epinephrine was $100 \%$ for the second molar and $84 \%$ for the first molar. The differences were not statistically significant between the 2 anaesthetic volumes. Loetscher et al[5] proved that second molars were anaesthetised successfully with PSANB, whereas only $88 \%$ of first molars were anaesthetised using only $1.8 \mathrm{~mL}$ of local anaesthesia. We used only $2 \mathrm{~mL}$ of local anaesthesia in both groups in our study, which is sufficient to achieve anaesthesia.

The size of the needle plays an important role in influencing the pain felt by the patient during injection. More pain is felt by the patient when bigger needle gauge is used for injection.[6] Malamed[1] advocated using 25-gauge short needle for PSANB. A 26-gauge long needle $(38 \mathrm{~mm})$ was used in our study for both groups. Dionne et al advocated not to advance needle more than $15 \mathrm{~mm}$ to prevent haematoma.[7] Pfeil et al[3] penetrated needle up to $18 \mathrm{~mm}$ with no incidence of haematoma formation. In our study both of the groups we penetrated a needle depth of $20 \mathrm{~mm}$ with no incidence of haematoma.

Literature review showed several complications of PSANB. If the needle is not placed properly in PSANB, it can result in various complications. Trauma to the pterygoid venous plexus of veins leads to haematoma, the most common complication. Bell's palsy, a rare complication occur due to placement of needle into the inferior part of parotid gland causing trauma to the cervicofacial division of the facial nerve. [8] PSA nerve block is a safe and simple procedure using curved needle. This would avoid all complications reported in the literature.[9] A rare case report with complication of transient diplopia is noted following local anaesthetic injection in posterior superior alveolar nerve block technique.[10] Sivaraman et al recommended short or curved needles. The needle must be advanced approximately $15 \mathrm{~mm}$ medially, superiorly and posteriorly at a 45 -degree angle to the maxillary occlusal plane following $x-y-z$ plane at the same time to reach the PSA nerve along the posterior surface of the maxilla.[11] In our study, we did not come across any complications while injecting for PSANB.

In our study, we used cold test using ice to check for pulpal anaesthesia. Petersson et al in their study confirmed that cold test scored better than heat or electrical tests.[12] Grace et al also reported similar findings. [13]
The primary drawback of bending a needle is that the bent portion was more prone to breakage. In our study we bent the 26-gauge needle in the middle third, which might weaken it. The bent long needle may deflect within the tissue, which can deviate the tip from the desired anatomical location leading to a lower success rate.

\section{CONCLUSION}

The study concludes that the PSANB using the straight needle technique can be safely and routinely used to achieve profound anaesthesia in the maxillary molar regions.

\section{REFERENCES}

[1] Malamed SF. Hand book of local anesthesia. $5^{\text {th }}$ edn. St. Louis: Mosby 2004.

[2] Jorgensen NB, Hayden J. Sedation, local and general anesthesia in dentistry. $3^{\text {rd }}$ edn. Philadelphia: Lea \& Febiger 1980.

[3] Pfeil L, Drum M, Reader A, et al. Anesthetic efficacy of 1.8 milliliters and 3.6 milliliters of $2 \%$ lidocaine with 1:100, 000 epinephrine for posterior superior alveolar nerve blocks. J Endod 2010;36(4):598-601.

[4] Singla H, Alexander M. Posterior superior alveolar nerve blocks: a randomized controlled, double blind trial. J Maxillofac Oral Surg 2015;14(2):423-31.

[5] Loetscher CA, Melton DC, Walton RE. Injection regimen for anesthesia of the maxillary first molar. J Am Dent Assoc 1988;117(2):337-40.

[6] Bennett CR. Monheim's local anesthesia and pain control in dental practice. $7^{\text {th }}$ edn. St. Louis: Mosby 1978.

[7] Dionne RA, Phero JC, Becker DE. Management of pain and anxiety in the dental office. $1^{\text {st }}$ edn. Philadelphia: WB Saunders 2002.

[8] Gupta N, Singh K, Sharma S. Hematoma - a complication of posterior superior alveolar nerve block. Journal of Dental Problems and Solutions 2015;2(1):15-16.

[9] Thangavelu K, Kumar NS, Kannan R, et al. Simple and safe posterior superior alveolar nerve block. Anesth Essays Res 2012;6(1): 74-7.

[10] Ghosh A, Vaibhav N, Raut R, et al. Ophthalmic complication following posterior superior alveolar nerve block for tooth extraction! a rare occurrence. J Maxillofac Oral Surg 2015;14(3):862-5.

[11] Hrishi TS, Gupta S. Posterior superior alveolar nerve block, a dilemma for dental practitioners - a case report. J Cont Med A Dent 2016;4(3):45-8.

[12] Petersson K, Soderstrom C, Kiani-Anarksi M, et al. Evaluation of the ability of thermal and electrical tests to register pulp vitality. Endod Dent Traumatol 1999;15(3):127-31.

[13] Hsaio-Wu GW, Susarala SM, White RR. Use of the cold test as a measure of pulpal anesthesia during endodontic therapy: a randomized, blinded, placebo controlled clinical trial. J Endod 2007;33(4):406-10. 